\title{
Efficacy and Safety of TENS and Duloxetine in Patients with Painful Diabetic Neuropathy: A Single Blind Randomized Clinical Trial
}

\author{
Bahram Naderi Nabi ${ }^{1}$ (D), Alia Saberi ${ }^{2}$ iD, Babak Bakhshayesh Eghbali 3 (D), \\ Mozaffar Hosseininezhad 3*(D), Gelareh Biazar 1 (D), Amir Abbasi Malekabadi 1(D), \\ Ladan Mirmansouri ${ }^{4}$
}

1. Anesthesiology Research Center, Guilan University of Medical Sciences, Rasht, Iran

2. Dept. of Anesthesiology, Alzahra Hospital, School of Medicine, Guilan University of Medical Sciences, Rasht, Iran

3. Neuroscience Research Center, Guilan University of Medical Sciences, Rasht, Iran

4. Dept. of Neurology, Poursina Hospital, School of Medicine, Guilan University of Medical Sciences, Rasht, Iran

5. Student Research Committee, School of Pharmacy, Guilan University of Medical Sciences, Rasht, Iran

\begin{tabular}{|c|c|}
\hline Article Info & ABSTRACT \\
\hline doi) $10.30699 / j a m b s .29 .136 .286$ & $\begin{array}{l}\text { Background \& Objective: Both duloxetine (DLX) and transcutaneous electrical } \\
\text { nerve stimulation (TENS) are recommended as safe and effective treatments for }\end{array}$ \\
\hline $\begin{array}{l}\text { Received: 2020/09/01; } \\
\text { Accepted: 2020/12/28; } \\
\text { Published Online: 04 Apr 2021; }\end{array}$ & $\begin{array}{l}\text { diabetic peripheral neuropathic pain. However, these methods have not been } \\
\text { compared. This study aimed to compare the efficacy of treatment by DLX and } \\
\text { TENS in diabetic neuropathy pain relief. }\end{array}$ \\
\hline $\begin{array}{l}\text { Use your device to scan and read the } \\
\text { article online }\end{array}$ & $\begin{array}{l}\text { Materials \& Methods: This survey was performed on } 60 \text { eligible diabetic patients } \\
\text { randomly divided into two groups of DLX ( } 20,40 \text {, and } 60 \mathrm{mg} / \text { day for weeks } 1,2 \text {, and } \\
3-12 \text {, respectively), and TENS ( } 20 \mathrm{~min}, 80 \mathrm{HZ}, 50 \mathrm{Amp}, 0.2 \mathrm{~ms} \text { Square pulses } 2-3 \\
\text { times sensory threshold). The participants were evaluated according to the numerical } \\
\text { rating scale (NRS) after four and twelve weeks of treatment. Moreover, adverse drug } \\
\text { reactions were documented during the study period. }\end{array}$ \\
\hline 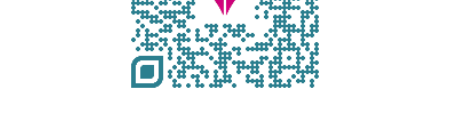 & $\begin{array}{l}\text { Results: Baseline demographic data had no significant difference between the two } \\
\text { groups }(P \geq 0.05) \text {. The average NRS scores were significantly lower in the DLX group } \\
\text { in both measurement times. At the end of weeks four }(P=0.01) \text { and } 12(P=0.001) \text {, the }\end{array}$ \\
\hline $\begin{array}{l}\text { Corresponding Information: } \\
\text { Mozaffar Hosseininezhad }\end{array}$ & patient in the TENS group reported any side effects, while $18 \%$ did in the DLX group. \\
\hline $\begin{array}{l}\text { Neuroscience Research Center, Guilan } \\
\text { University of Medical Sciences, Rasht, } \\
\text { Iran } \\
\text { E-Mail: } \\
\text { dr.hoseinnezhad2020@gmail.com }\end{array}$ & $\begin{array}{l}\text { Conclusion: We found that both DLX and TENS were effective and safe for the } \\
\text { management of painful diabetic neuropathy. The DLX seemed to be better, } \\
\text { compared to TENS. However, in some conditions, such as drug intolerance or } \\
\text { contraindication for medications, TENS could be a proper intervention. }\end{array}$ \\
\hline
\end{tabular}

Keywords: Aerobic training, Irisin, Resistance training

Copyright $\odot$ 2021, This is an original open-access article distributed under the terms of the Creative Commons Attribution-noncommercial 4.0 International License which permits
copy and redistribution of the material just in noncommercial usages with proper citation.

\section{Introduction}

Diabetic peripheral neuropathic pain (DPNP) is a common and disabling complication of diabetes affecting almost $50 \%$ of diabetic patients (1). It presents as a chronic symmetrical and severe shooting pain leading to high health costs, disability of patients, and poor quality of life (2). The pathogenesis of DPNP is attributed to the interaction between the nervous and immune systems $(3,4)$.

Various pharmacological and non-pharmacological interventions have been used to control DPNP. However, it remains a great challenge for physicians (5-7). Therefore, it is crucial to continue investigations toward influential treatments with the least adverse effects.
According to the literature, few studies have compared the efficacy of transcutaneous electrical nerve stimulation (TENS), as a non-pharmacological treatment, with pharmacologic agents. In the present study, the pain relief properties of TENS and duloxetine (DLX) were compared in DPNP.

TENS has been used widely in various painful conditions as a safe, easy to use, and inexpensive method with no serious adverse effects (8). Although the efficacy of TENS in the control of chronic pain has been supported by previous human studies, few trials are available concerning painful diabetic neuropathy (9). Furthermore, TENS is known as an influential safemanagement strategy (10). However, there is no 
consensus on the way of optimizing the impacts of this method (11).

The DLX, as another studied drug, is a serotoninnorepinephrine reuptake inhibitor causing an increase in the local concentration of specific neurotransmitters in the descending pathways of the brain and spinal cord. It has been known to have neuroprotective properties $(2,12)$.

Despite few investigations on the safety and efficacy of these therapeutic methods, comparative studies focusing on the Iranian population are rare and this is the first survey comparing these treatments for DPNP. Consequently, the current research aimed to compare the efficacy and safety of TENS and DLX in patients with DPNP.

\section{Materials and Methods}

This single-blind clinical trial was conducted in the Guilan pain clinic during February 2019-April 2020. The study protocol was approved by the Ethics Committee of Guilan University with the ethical code of IR.GUMS.REC.1398.052 and was registered in the Iranian Registry of Clinical Trials (IRCT20110413006186N13).

Firstly, informed consent was obtained by giving a complete explanation about the survey to the participants. Our subjects were selected from the patients who were referred to our pain clinic by neurologists.

The inclusion criteria entailed being affected by diabetes type I and II, age of over 18 years, and being diagnosed with DPNP. The diagnosis was confirmed by an experienced neurologist based on the American Diabetes Association criteria (13). The DPNP was diagnosed according to the Michigan Neuropathy Screening Instrument scale (14) as pain severity $\geq 4$ based on the Numerical Rating Scale (NRS) $(0=$ no pain to $10=$ the most severe pain) and resistance to the conventional treatments for at least six months.

The exclusion criteria included: 1) contraindications or history of adverse reactions to DLX, 2) hepatic, heart, or renal failure, 3) hemoglobin A1c>8 mg\%, 4) analgesics consumption, 5) having received serotonergic medications within 14 days prior to the study, 6) uncontrolled hypertension, 7) being pregnant, 8) smoking, 9) psychological disorders, 10) epilepsy or any other neuropathies, 11) pace marker or implantable cardioverter-defibrillator, 12) irritation or inflammation at TENS site, and 13) history of receiving TENS.

All patients were advised to not change their diabetes control medications and other vital drugs, such as antihypertensive and lipid-lowering agents during the study period unless it was necessary. Three months before the study, all patients stopped receiving any types of analgesic drugs and underwent treatment with gabapentin 300-600 mg/daily. In case ADRs occurred or proper pain relief was achieved the patient was excluded from the survey.

Eligible diabetic patients enrolled in the survey and were randomly divided into two groups of DLX (20, 40, and $60 \mathrm{mg} /$ day for weeks 1,2 , and 3-12, respectively) and TENS (20 $\mathrm{min}, 80 \mathrm{HZ}, 50 \mathrm{Amp}, 0.2$ ms Square pulses 2-3 times sensory threshold). They were evaluated according to the NRS one and three months after starting the treatment. During the course of the study, the participants were asked to report any adverse effects related to their treatment methods and the reports were documented precisely. The patients could not be blinded due to the obvious difference in the type of treatments leading to a single-blind study.

\section{Results}

A total of 246 diabetic patients were interviewed in terms of eligibility and 107 were screened. Because of different reasons 35 individuals were excluded. Finally, 72 patients were selected based on the inclusion and exclusion criteria and were randomly assigned to two equal groups of DLX and TENS. In the DLX group, 12 patients discontinued treatment due to intolerability and were replaced with new cases. All patients in the TENS group completed the study. The demographic and primary clinical data of the two groups showed no significant difference $(P \geq 0.05)$ (Table 1). The mean severity of DPNP at three different time sections based on the NRS scores has been shown in Table 2.

Repeated measure analysis displayed a significant trend of changes within three months $(P<0.001)$. (Figure 1). The mean NRS scores were significantly lower in the DLX group than the TENS group at the end of the first $(P=0.01)$ and third months $(P=0.001)$. In the DLX group, $18(60 \%)$ patients reported at least one ADR, including dry mouth, vertigo, and constipation. In the TENS group, none of the studied cases reported serious side effects and only a few people complained of buzzing, tingling, or prickling sensation or transient allergy to the adhesive pads. 
Table 1. Patients' demographic and clinical characteristics.

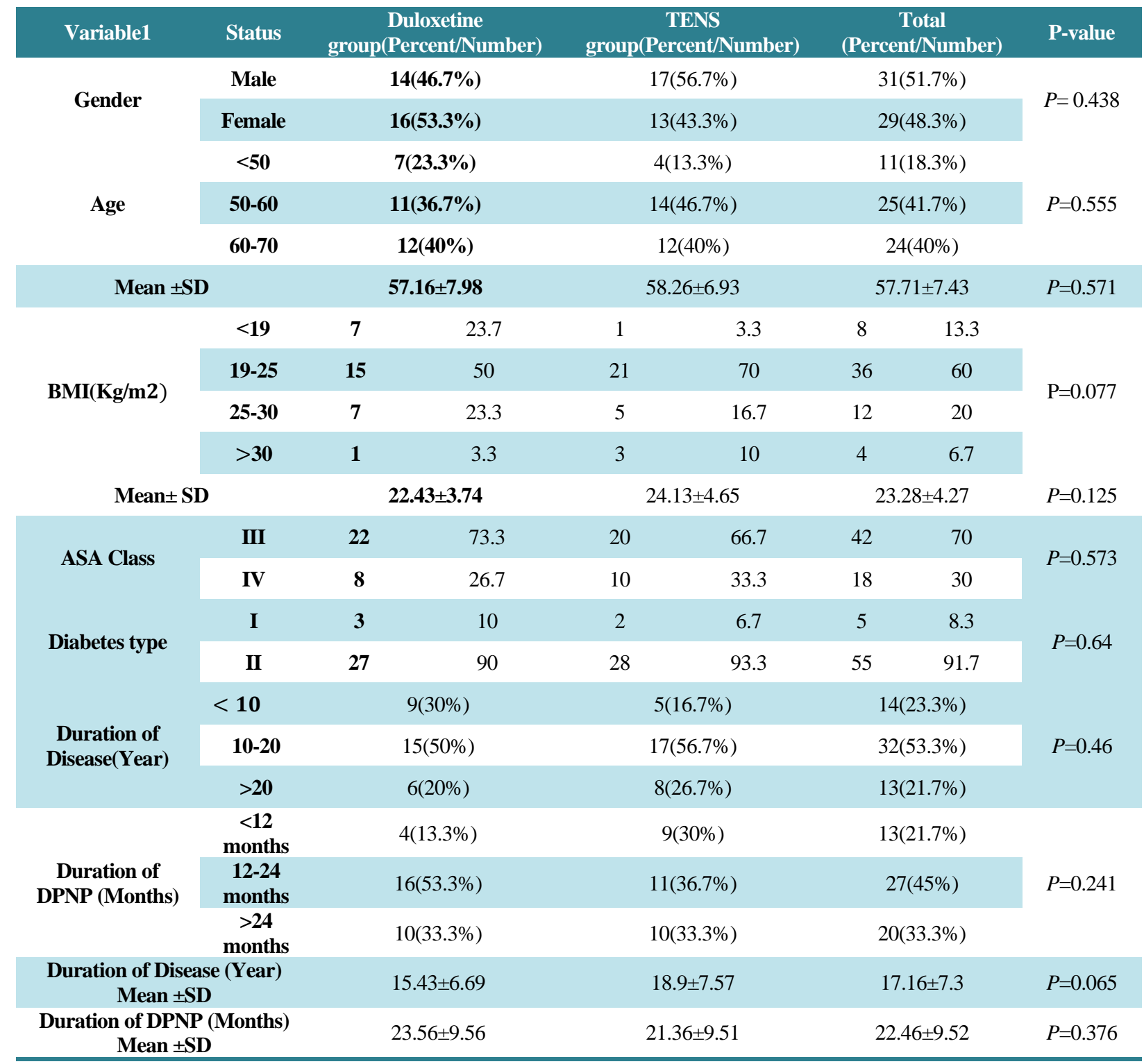

Table 2. Comparison of patients' DPNP intensity by NRS, at three measurement point times of the study

\begin{tabular}{cccccc} 
Measurement times & Pre-Treatment & 1st Month & 3rd-month & $\begin{array}{c}\text { P-value } \\
\text { within } \\
\text { groups }\end{array}$ & $\begin{array}{c}\text { P-value } \\
\text { between } \\
\text { groups }\end{array}$ \\
Duloxetine & $5.23 \pm 0.85$ & $3.43 \pm 0.93$ & $2.76 \pm 0.67$ & $\begin{array}{c}\mathrm{F}=230.1 \\
P=0.0001\end{array}$ & $\mathrm{~F}=11.18$ \\
TENS & $5.2 \pm 0.76$ & $4.03 \pm 0.8$ & $3.43 \pm 0.77$ & $\mathrm{~F}=128.7$ & $P=0.0001$ \\
P-value & $\mathrm{F}=0.159$ & $\mathrm{~F}=2.56$ & $\mathrm{~F}=3.54$ & & \\
\hline$P=0.874$ & $P=0.01$ & $P=0.001$ & & \\
\hline
\end{tabular}




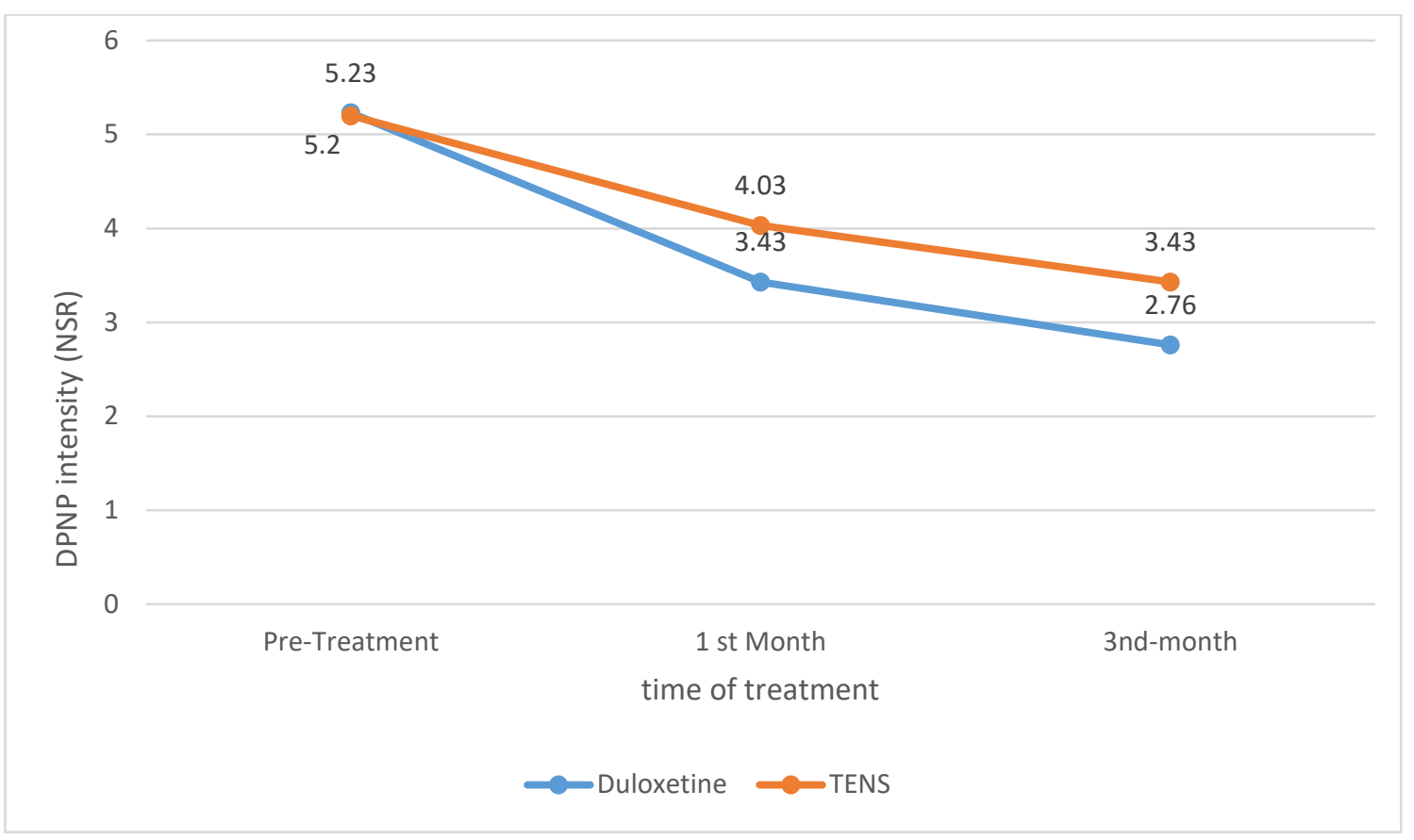

Figure 1. NRS score at different time sections in two groups

\section{Discussion}

Despite providing detailed information about the pathophysiology of DPNP and considerable researches in this field, pain control is not completely successful yet. The first and main approach to prevent and reverse is proper and tight glucose level control (15). In this study, the effectiveness of the two treatment options was investigated.

In line with the findings of previous studies, we found both interventions to be effective and safe. Although DLX was significantly better, few patients were excluded during the survey due to intolerable ADRs. However, all patients in the TENS group finished the follow-up without any adverse reaction. Contrary to the DLX group, the significant pain relief in the TENS group was transient and after almost two hours, patients suffered from refractory pain but not with the same severity. Considering the potential DLX adverse effects, patients resistant to the conventional drugs or those affected by severe side effects could benefit from this non-pharmacological adjuvant treatment. The latter result could be the practical aspect of this study.

Experimental studies have demonstrated that TENS inhibits the raised irritability of nociceptive neurons, which occurs following inflammation or nerve injury. In addition, TENS activates endogenous opioid receptors leading to the activation of central inhibitory pathways $(8,9)$.

DLX has been known as the first line of pharmacological therapy (4). Javeed et al. in a randomized controlled trial compared the efficacy of DLX $60 \mathrm{mg}$ daily with Amitriptyline $75 \mathrm{mg}$ daily on the reduction of diabetic neuropathy pain. Moreover, any side effect was documented during the study period. In their study, a total of 200 patients aged 2065 years and symptomatic for at least six months were divided into two equal groups. In a six weeks followup, patients in the DLX group significantly showed better results (16).

Zakerkish et al. in a study similar to our work, compared nortriptyline and TENS as a pharmacologic and a non-pharmacologic option, respectively. They found that both methods were safe and effective. However, patients in the nortriptyline group showed a better therapeutic response, compared to the individuals in the TENS group. The patients in the intervention group experienced a significant drop in the VAS score. Similar to the present study, only $15 \%$ of the cases reported subtle side effects, such as transient cramps. They also revealed that although patients with severe pain benefited from nortriptyline with more stable effects, TENS was markedly more accepted with significantly fewer side effects (5).

Consistent with our results, Joharchi et al. in Iran reported that $74 \%$ of diabetic patients receiving DLX with the average dose of $60 \mathrm{mg}$ daily showed at least one adverse drug reaction, while $26.7 \%$ of the participants were excluded from the survey. These authors believed that other therapeutic options, such as pregabalin could be a better choice for this purpose (17). In contrast, Majdinasab et al. observed that $90.38 \%$ of their cases receiving $60 \mathrm{mg}$ DLX daily, well-tolerated the treatment and markedly improved (12). 
Devi et al. in India reported that DLX was safe and tolerable in their cases with a flexible range of dosage (20-80 mg/day) (18). In the study performed by Yasuda et al. in Japan, the average effective and tolerable dose of DLX was $40 \mathrm{mg} /$ day (19). Raskin et al. in a clinical trial evaluated the high dosage regimes of DLX (120 $\mathrm{mg}$ /daily) in people from Brazil, Canada, Argentina, and Australia. A total of 449 patients participated and $21.8 \%$ of them discontinued the study due to ADRs. The reported ADRs entailed nausea, dizziness, vomiting, fatigue, and somnolence (20).

The average daily therapeutic and safe dosage of DLX was found as 53.9, 55.2, and 60-120 mg in German, American, and English individuals, respectively (21-23). In line with the present investigation, Nabi et al. (24) and Yadav et al. (25) demonstrated the positive effects of TENS on DPNP (5). On the other hand, Oyibo et al. did not observe any significant improvements in these patients after six weeks of continuous treatment (26).

The controversy in the findings could be partly explained by different methodologies, the characteristics of the studied population, and pain evaluation instruments. Obviously, the measurement of pain severity based on a self-report scale depends on the perception of individuals and definition of pain severity, which might vary person by person. Differences in average BMI, social mental health condition, nutrition status, serum albumin levels, and genetic polymorphism should be considered as well (27).

Moreover, studies have highlighted the importance of the role of race and region on drug reactions and therapeutic response (28). Fox et al. demonstrated the role of serotonin transporter gene polymorphism in adverse reactions to DLX (29). Previous studies have well described the impacts of ethnics and region on hepatic metabolism. It is reported that almost $24 \%$ of Iranians have a lower rate of hepatic metabolism due to the specific cytochrome $2 \mathrm{D}_{6}\left(\mathrm{CYP}_{2} \mathrm{D}_{6}\right)$ and are more likely to be affected by drug side effects (30). For example, the safe and effective dosage of some medications, such as warfarin and tricyclic antidepressants are lower in the Iranian population, compared to Europeans and Americans (31).

We recommend further well-planned studies with larger sample size, longer follow-up, and more outcomes. In addition, the influence of other factors, including health status, mental condition, nutrition, and serum albumin level on the efficacy and safety margins of the treatments should be evaluated.

Although this study revealed valuable information in terms of pain relief in DPNP, we encountered some limitations. Firstly, it was the first study on direct comparison of DLX, as the first-line drug in DPNP management, with TENS, as an effective nonpharmacological option in the Iranian population. Furthermore, this investigation was a single-center study with small sample size and a limited follow-up of three months. Moreover, the assessment of patients was only based on the NRS and all detailed diabetes parameters were not evaluated.

\section{Conclusion}

Both TENS and DLX could effectively reduce DPNP. Although DLX showed superior results, it was associated with more adverse effects. TENS was well tolerated with short-term and transient pain relief impacts. Decision-making to choose the proper treatment depends on the conditions and pain severity of patients. Moreover, the combination of TENS with medications may diminish drug dosage creating more compliance.

\section{Author Contribution}

Conception and design of the article: BNN. acquisition of data: AAM and LM. analysis and interpretation of data: AS and BBE. Writing of the article: GB. Critical revision of its content: $\mathrm{MH}$.

\section{Acknowledgments}

The present article is part of Dr. Amir Abbasi Malekabadi thesis, under the supervision of Dr. Bahram Naderi Nabi at the Department of Anesthesiology of Guilan University of Medical Sciences. We also thank Ms. Mahin Tayefeh Ashrafiyeh and Ms Mohadese Ahmadi, members of Anesthesiology Research Center for their good corporations and all the patients who participated in the survey.

\section{Ethical Approval}

The ethics committee of GUMS approved this study (ethical code: IR.GUMS.REC.1398.052). It was registered in the Iranian Registry of Clinical Trials website: http://www.irct.ir and the registration number is IRCT20110413006186N13.

\section{Conflict of Interest}

The authors reported no conflicts of interest.

\section{Funding/Support}

This study was not financially supported. 


\section{References}

1. Callaghan BC, Cheng HT, Stables CL, Smith AL, Feldman EL. Diabetic neuropathy: clinical manifestations and current treatments. Lancet Neurol.

2012;11(6):521-34 [DOI:10.1016/S1474-4422(12)70065-0]

2. Khdour MR. Treatment of diabetic peripheral neuropathy: a review. J Pharm Pharmacol. 2020;72(7):863-72.

[DOI:10.1111/jphp.13241]

3. Austin PJ, Moalem-Taylor G. The neuroimmune balance in neuropathic pain: involvement of inflammatory immune cells, immune-like glial cells and cytokines. J Neuroimmunol. 2010;229(1-2):26-50. [DOI:10.1016/j.jneuroim.2010.08.013]

4. Tawfik MK, Helmy SA, Badran DI, Zaitone SA. Neuroprotective effect of duloxetine in a mouse model of diabetic neuropathy: role of glia suppressing mechanisms. Life Sci. 2018;205:113-24.

[DOI:10.1016/j.Ifs.2018.05.025]

5. Zakerkish M, Raeisi D, Rafie S, et al. Comparison of efficacy of nortriptyline versus transcutaneous electrical nerve stimulation on painful peripheral neuropathy in patients with diabetes. Romanian J Diabet Nutr Metab Dis. 2019;26(4):401-11. [DOI:10.2478/rjdnmd2019-0043]

6. Gomar A, Hosseini A, Mirazi N, Gomar M. Effect of hydroethanolic extract of Rubus fruticosus on neuropathic pain in wistar diabetic rats. Caspian J Neurol Sci. 2015;1(1):27-34. [DOI:10.18869/acadpub.cjns.1.1.27]

7. Lyman D. B cell therapy to treat an axonal neuropathy in mixed connective tissue disease. Caspian J Neurol Sci. 2017;3(1):46-53. [DOI: 10.18869/acadpub.cjns.3.8.46]

8. Gewandter JS, Chaudari J, Ibegbu C, et al. Wireless transcutaneous electrical nerve stimulation device for chemotherapy-induced peripheral neuropathy: an open-label feasibility study. Support Care Cancer. 2019;27(5):176574. [DOI:10.1007/s00520-018-4424-6]

9. Gibson W, Wand BM, O'Connell NE. Transcutaneous electrical nerve stimulation (TENS) for neuropathic pain in adults. Coch Database Sys Rev. $2017 \quad$ (9). [DOI: 10.1002/14651858.CD011976.pub2]

10. Ogle T, Alexander K, Miaskowski C, Yates P. Systematic review of the effectiveness of selfinitiated interventions to decrease pain and sensory disturbances associated with peripheral neuropathy. J Cancer Survivorship.
2020;14:444-64. [DOI:10.1007/s11764-02000861-3]

11. Mokhtari T, Ren Q, Li N, Wang F, Bi Y, Hu L. Transcutaneous electrical nerve stimulation in relieving neuropathic pain: basic mechanisms and clinical applications. Curr Pain Headache Rep. 2020 ; 24(4): 14 p.Available from: http://europepmc.org/abstract/MED/32072323 [DOI:10.1007/s11916-020-0846-1]

12. Majdinasab N, Kaveyani H, Azizi M. A comparative double-blind randomized study on the effectiveness of duloxetine and gabapentin on painful diabetic peripheral polyneuropathy. Drug Design Develop Ther. 2019;13:1985. [DOI:10.2147/DDDT.S185995]

13. Davies MJ, D'Alessio DA, Fradkin J, et al. Management of hyperglycaemia in type 2 diabetes, 2018. A consensus report by the American Diabetes Association (ADA) and the European Association for the Study of Diabetes (EASD). Diabetologia. 2018;61(12):2461-98. [DOI: 10.1007/s00125-018-4729-5]

14. Herman W, Pop-Busui R, Braffett B, et al. Use of the Michigan Neuropathy Screening Instrument as a measure of distal symmetrical peripheral neuropathy in type 1 diabetes: results from the diabetes control and complications trial/epidemiology of diabetes interventions and complications. Diabet Med. 2012;29(7):937-44. [DOI:10.1111/j.1464-5491.2012.03644.x]

15. Snyder MJ, Gibbs LM, Lindsay TJ. Treating painful diabetic peripheral neuropathy: an update. Am Fam Physic. 2016;94(3):227-34.

16. Javeed A, Alam MA, Maqsood A, Azher A, Arif M, Qayyum A. Comparison of efficacy of duloxetine with amitriptyline in terms of reduction in frequency of pain in the patients of diabetic neuropathy. Prof Med J. 2020;27(09):1891-4. [DOI: 10.29309/TPM]/2020.27.09.4289]

17. Joharchi K, Memari M, Azargashb E, Saadat N. Efficacy and safety of duloxetine and Pregabalin in Iranian patients with diabetic peripheral neuropathic pain: a double-blind, randomized clinical trial. J Diabet Metab Disorder. 2019;18(2):575-82. [DOI:10.1007/s40200019-00427-w]

18. Devi P, Madhu K, Ganapathy B, Sarma G, John L, Kulkarni C. Evaluation of efficacy and safety of gabapentin, duloxetine, and pregabalin in patients with painful diabetic peripheral neuropathy. Indian J Pharmacol. 2012;44(1):51. [DOI:10.4103/0253-7613.91867]

19. Yasuda H, Hotta N, Kasuga M, Yamada T, et al. Efficacy and safety of $40 \mathrm{mg}$ or $60 \mathrm{mg}$ duloxetine in $\mathbf{J}$ apanese adults with diabetic 
neuropathic pain: Results from a randomized, 52-week, open-label study. J Diabet Invest. 2016;7(1):100-8. [DOI:10.1111/jdi.12361]

20. Raskin J, Wang F, Pritchett YL, Goldstein DJ. Duloxetine for patients with diabetic peripheral neuropathic pain: a 6-month open-label safety study. Pain Med. 2006;7(5):373-85. [DOI: 10.1111/j.1526-4637.2006.00207.x]

21. Happich M, Schneider E, Boess FG, et al. Effectiveness of duloxetine compared with pregabalin and gabapentin in diabetic peripheral neuropathic pain: results from a German observational study. Clin J Pain. 2014;30(10):875-85.

\section{[DOI:10.1097/AJP.0000000000000057]}

22. Boyle J, Eriksson ME, Gribble L, et al. Randomized, placebo-controlled comparison of amitriptyline, duloxetine, and pregabalin in patients with chronic diabetic peripheral neuropathic pain: impact on pain, polysomnographic sleep, daytime functioning, and quality of life. Diabet Care. 2012;35(12):2451-8. [DOI:10.2337/dc120656]

23. Sun $\mathrm{P}$, Zhao $\mathrm{Y}$, Zhao Z, Bernauer M, Watson $\mathrm{P}$. Dosing pattern comparison between duloxetine and pregabalin among patients with diabetic peripheral neuropathic pain. Pain Pract. 2012;12(8):641-8. [DOI:10.1111/j.15332500.2012.00537.x]

24. Nabi BN, Sedighinejad A, Haghighi M, et al. Comparison of transcutaneous electrical nerve stimulation and pulsed radiofrequency sympathectomy for treating painful diabetic neuropathy. Anesthesiol Pain Med. 2015;5(5). [DOI:10.5812/aapm.29280]
25. Yadav AO, Ramteke G. Effectiveness of transcutaneous electrical nerve stimulator (TENS) in reducing neuropathic pain in patients with diabetic neuropathy. Indian $\mathbf{J}$ Physiother Occup Ther. 2013;7(1):11.

26. Oyibo S, Breislin K, Boulton A. Electrical stimulation therapy through stocking electrodes for painful diabetic neuropathy: a double blind, controlled crossover study. Diabet Med. 2004;21(8):940-4. [DOI: 10.1111/].14645491.2004.01243.x]

27. Alomar MJ. Factors affecting the development of adverse drug reactions. Saudi Pharmaceut J. 2014;22(2):83-94. [DOI: 10.1016/i.jsps.2013.02.003]

28. Bushra R, Aslam N, Khan AY. Food-drug interactions. Oman Med J. 2011;26(2):77. [DOI:10.5001/omj.2011.21]

29. Fox MA, Jensen CL, Gallagher PS, Murphy DL. Receptor mediation of exaggerated responses to serotonin-enhancing drugs in serotonin transporter (SERT)-deficient mice. Neuropharmacol. 2007;53(5):643-56. [DOI:10.1016/j.neuropharm.2007.07.009]

30. Bagheri A, Kamalidehghan B, Haghshenas M, et al. Prevalence of the CYP2D6* 10 (C100T), * 4 (G1846A), and* 14 (G1758A) alleles among Iranians of different ethnicities. Drug Des, Devel Ther. 2015;9:2627. [DOI: 10.2147/DDDT.S79709]

31. Razazian N, Baziyar M, Moradian N, Afshari D, Bostani A, Mahmoodi M. Evaluation of the efficacy and safety of pregabalin, venlafaxine, and carbamazepine in patients with painful diabetic peripheral neuropathy: a randomized, double-blind trial. Neurosci. 2014;19(3):192.

\section{How to Cite This Article:}

Naderi Nabi B, Saberi A, Bakhshayesh Eghbali B, Hosseininezhad M, Biazar G, Abbasi Malekabadi A et al Efficacy and Safety of TENS and Duloxetine in Patients with Painful Diabetic Neuropathy: A Single Blind Randomized Clinical Trial. J Adv Med Biomed Res. 2021; 29 (136) :287-293

Download citation: BibTeX $|\underline{\text { RIS }}| \underline{\text { EndNote }}|\underline{\underline{M e d l a r s}}| \underline{\text { ProCite }} \mid$ Reference Manager $\mid \underline{\text { RefWorks }}$

\section{Send citation to:}

(3) Mendeley 2 Zotero RefWorks $\underline{\text { RefWorks }}$ 